\title{
Cefaleia Pós-Punção Lombar Diagnóstica por Cefaleia Persistente
}

\section{Post-Diagnostic Lumbar Puncture Headache for Persistent Headache}

Marta Santana ${ }^{1}$, António Araújo²

Autor Correspondente: Marta Pinheiro Tenreiro Santana [martaptsantana@gmail.com] Rua Dom António Francisco Marques, lote 43, $1^{\circ}$ Dto, 2005-352 Santarém, Portugal

\section{RESUMO}

A complicação mais frequente da punção lombar é a cefaleia pós-punção lombar, que decorre da depleção do líquido cefalorraquidiano e surge nos primeiros cinco dias após a punção lombar. Destaca-se pelo seu caráter postural e distribuição frontal-occipital. Reporta-se o caso clínico de uma doente de 33 anos que desenvolve cefaleia pós-punção lombar diagnóstica. Uma vez que se trata de um procedimento recorrente na prática clínica, torna-se fulcral aplicar diligências técnicas e de seleção de material, de forma a reduzir a incidência da síndrome pós-punção lombar. Embora a sua evolução seja geralmente benigna, existem complicações sérias associadas à persistência de baixas pressões do líquido cefalorraquidiano, pelo que requer vigilância clínica e imagiológica.

PALAVRAS-CHAVE: Cefaleia; Meningite; Punção Lombar

\section{ABSTRACT}

The most frequent complication of lumbar puncture is post-lumbar puncture headache, which is due to the cerebrospinal fluid depletion and arises in the first five days after the lumbar puncture. It stands out for being postural and having frontal-occipital distribution. This is a case report of a 33-year-old woman who develops post-diagnostic lumbar puncture headache. Since it is a recurrent procedure in clinical practice, it becomes crucial to be meticulous in applying techniques and selecting material to reduce the incidence of lumbar puncture syndrome. Although it is usually benign, there are serious complications associated with the persistence of low cerebrospinal fluid pressures, reason why it requires clinical and imaging surveillance. KEYWORDS: Headache; Meningitis; Spinal Puncture 


\section{INTRODUÇÃO}

A punção lombar diagnóstica é um procedimento invasivo com indicações específicas, como a exclusão de hemorragia subaracnoideia, a investigação de doenças inflamatórias ou infeciosas do sistema nervoso central, a investigação de distúrbios neurológicos e a medição indireta da pressão intracraniana. ${ }^{1}$ A punção lombar não diagnóstica é realizada frequentemente no contexto da anestesia ou na administração de agentes terapêuticos. A complicação mais comum é a cefaleia pós-punção lombar (CPPL), que ocorre com uma frequência de cerca de $32 \% .{ }^{1}$

Segundo a International Classification of Headache Disorders, ${ }^{2}$ a CPPL surge nos primeiros cinco dias após a punção lombar e desaparece espontaneamente em duas semanas. Os fatores de risco para ocorrência de CPPL incluem idade entre os 31 e os 50 anos, sexo feminino, gravidez, história de cefaleias e não ser fumador. ${ }^{3}$

A utilização de agulha antitraumática Whitacre ou Sprotte de 22 gauge demonstrou uma redução significativa da incidência de CPPL, quando comparada com a agulha clássica Quincke. ${ }^{1}$ A orientação longitudinal do bisel, por separar as fibras da dura-máter em vez de as seccionar, associa-se também a um menor risco de CPPL. ${ }^{3}$

A CPPL tem uma distribuição frontal-occipital, agrava após 15 minutos de ortostatismo e alivia após 30 minutos de decúbito dorsal. ${ }^{4}$ Pode acompanhar-se de rigidez cervical, fotofobia, náuseas, zumbidos, hipoacusia e diplopia, por tração do quarto ou sexto nervos cranianos. A dor pode irradiar para os ombros ou para a região cervical.1,3

Existem dois mecanismos fisiopatológicos descritos para a CPPL, ${ }^{3}$ ambos relacionados com a diminuição da pressão do líquido cefalorraquidiano, pela sua aspiração e eventuais perdas posteriores: por um lado, as funções de lubrificação e amortecimento normalmente asseguradas pelo líquido ficam comprometidas, provocando a tração de estruturas intracranianas sensíveis à dor; por outro lado, ocorre vasodilatação intracraniana compensatória, que causa cefaleia. Por sua vez, o volume de líquido cefalorraquidiano removido não está relacionado com a ocorrência de cefaleia pós-punção lombar. ${ }^{4}$

O diagnóstico da CPPL é maioritariamente clínico, podendo ser confirmado pela medição da pressão intracraniana por nova punção lombar ou por exames de imagem. Na ressonância magnética cranioencefálica pode identificar-se a tumefação difusa das meninges após a administração de contraste de gadolínio, coleções subdurais, turgescência das estruturas venosas e hiperemia

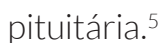

Pressões do líquido cefalorraquidiano persistentemente baixas podem ter complicações sérias, como trombose venosa central, crises convulsivas, paralisia de nervos cranianos, hematoma subdural, ou lesões ao nível do tronco cerebral, que se podem traduzir em estado de coma. ${ }^{3}$ A trombose venosa central secundária a hipotensão do líquido cefalorraquidiano pode ser explicada por três mecanismos: por um lado, ocorre dilatação venosa compensatória e consequente diminuição da velocidade do fluxo sanguíneo; por outro lado, a perda de líquido cefalorraquidiano condiciona o estiramento das veias, com lesão do endotélio; por último, a depleção de líquido cefalorraquidiano determina a redução da absorção de líquido para as veias cerebrais, promovendo o aumento da viscosidade do sangue venoso. A cefaleia, que pode ter início agudo ou insidioso, é o sintoma mais precoce da trombose venosa central e pode associar-se a diminuição da acuidade visual e perda da consciência. Clinicamente, esta cefaleia contrasta com a CPPL por não ter componente ortostático, ${ }^{5}$ devendo proceder-se a investigação imagiológica confirmatória.

A punção lombar pode ter outras complicações, como o hematoma subdural, trombose subdural e encefalopatia reversível, pelo que, perante sinais neurológicos ou cefaleia não-postural, estas etiologias devem ser excluídas. ${ }^{3}$

\section{RELATO DE CASO}

Doente do sexo feminino, 33 anos, melanodérmica, com antecedentes de enxaqueca não medicada, não fumadora, recorreu ao Serviço de Urgência do Hospital de São José no dia 29 de agosto por episódio de cefaleia intensa de aparecimento agudo no dia 27 do mesmo mês. A doente relata a toma de paracetamol e ibuprofeno, que não aliviaram a dor. A dor era difusa e constante e não apresentava fatores de alívio nem de agravamento. Negava febre, náuseas, vómitos, fotofobia, vertigens, palpitações e rigidez da nuca. Negava hábitos alcoólicos ou toxicofílicos.

A doente foi internada, realizou tomografia computorizada de crânio e ressonância magnética cranioencefálica, nas quais não se identificaram alterações apreciáveis. Na manhã do dia 30 de agosto, realizou punção lombar diagnóstica e, nessa tarde, foi transferida para o Hospital dos Capuchos. O exame foi compatível com encefalite pelo vírus de Epstein-Barr, tendo sido iniciadas terapêuticas antiviral e analgésica, que foram eficazes na remissão da sintomatologia. No dia 1 de setembro, iniciou episódio de cefaleia intensa frontal-occipital, de aparecimento súbito, que aliviava com o decúbito e com a ingestão de cafeína e agravava com a elevação do tronco. A dor era acompanhada de rigidez cervical, fotofobia, intolerância ao ruído e náuseas, e irradiava para os ombros. No mesmo dia, a doente foi transferida para o Hospital CUF Descobertas. Iniciou terapêutica com paracetamol, ibuprofeno e solução polieletrolítica $2 \mathrm{~L}$, que se revelam insuficientes na remissão da sintomatologia. 
À data da entrevista clínica, no dia 2 de setembro, a doente apresentava-se vígil, lúcida, colaborante, orientada e apirética. Permaneceu sob vigilância e manteve a terapêutica, tendo havido remitência da sintomatologia no dia 3 de setembro, obviando a necessidade de terapêutica invasiva.

\section{DISCUSSÃO}

Por ter 33 anos de idade, ser do sexo feminino, ter antecedentes de cefaleias e não ser fumadora, a doente do caso clínico exposto reúne os principais fatores de risco para CPPL. A abordagem da CPPL nas primeiras 48 horas deve ser conservadora, sendo suficiente para a remissão da sintomatologia em cerca de $85 \%$ dos casos. ${ }^{3}$ Estas medidas incluem repouso em supino, hidratação intravenosa, suplementação de cafeína e medicação analgésica. O repouso em decúbito ventral pode aliviar a CPPL uma vez que o aumento da pressão intra-abdominal eleva a pressão do líquido cefalorraquidiano ${ }^{3}$. Como na maioria dos casos de CPPL, no caso clínico exposto houve remissão da sintomatologia na primeira semana, apenas com terapêutica conservadora.

Caso houvesse persistência da sintomatologia após 48 horas, considerar-se-ia iniciar o tratamento invasivo de primeira linha, que consiste na injeção epidural de sangue autólogo (autologous epidural blood patch). ${ }^{3}$ Este procedimento pretende selar o local da punção, através da formação de um coágulo de fibrina 18 a 24 horas após a injeção. Para além disso, possui um efeito imediato no alívio da cefaleia, na medida em que aumenta a pressão do líquido cefalorraquidiano, o que provoca a vasoconstrição reflexa cerebral. A injeção deve ser efetuada ao nível do espaço intervertebral imediatamente abaixo do espaço intervertebral da punção lombar anterior, uma vez que o sangue se dirige no sentido cefálico após a sua injeção no espaço epidural lombar. São injetados lentamente $20 \mathrm{~mL}$ de sangue, devendo o procedimento ser interrompido se o doente referir aparecimento de dor lombar, torácica ou cervical, dor radicular nos membros inferiores ou agravamento da cefaleia. A falha do tratamento pode refletir a persistência do trajeto fistuloso, devendo, nestes casos, proceder-se a uma segunda injeção epidural de sangue autólogo. ${ }^{6}$

Quando todas estas medidas falham, e na presença de uma perda persistente de líquido cefalorraquidiano, pode ser necessário o encerramento cirúrgico do defeito dural.

Uma vez que a persistência de baixas pressões do líquido cefalorraquidiano pode culminar num evento trombótico venoso central, a doente deve manter-se sob vigilância e repetir exames de imagem, como a tomografia computorizada de crânio ou a ressonância magnética cranioencefálica. ${ }^{4}$

\section{CONCLUSÃO}

A punção lombar é um procedimento recorrente no diagnóstico neurológico. Associa-se frequentemente à síndrome de cefaleia pós-punção lombar que, embora tenha uma evolução benigna e autolimitada na maioria dos casos, pode ser incapacitante, exigir tratamento invasivo e protelar a alta clínica de doentes internados. Nesta medida, a prevenção da CPPL deve ser o objetivo primeiro dos clínicos, através do apuramento técnico e da seleção de agulhas que comportam um menor risco.

CONFLITOS DE INTERESSE: Os autores declaram não ter qualquer conflito de interesse na realização do presente trabalho.

FONTES DE FINANCIAMENTO: Não houve qualquer fonte de financiamento na realização do presente trabalho.

CONFIDENCIALIDADE DOS DADOS: Os autores declaram ter seguido os protocolos da sua instituição acerca da publicação dos dados de doentes.

PROTEÇÃO DE PESSOAS E ANIMAIS: Os autores declaram que os procedimentos seguidos na elaboração do presente trabalho estão em conformidade com as normas das comissões de investigação clínica e de ética, bem como da declaração de Helsínquia e da Associação Médica Mundial.

CONFLICTS OF INTEREST: The authors declare that they have no conflicts of interest.

FINANCIAL SUPPORT: This work has not received any contribution, grant or scholarship.

CONFIDENTIALITY OF DATA: The authors declare that they have followed the protocols of their work center on the publication of data from patients.

PROTECTION OF HUMAN AND ANIMAL SUBJECTS: The authors declare that the procedures followed were in accordance with the regulations of the relevant clinical research ethics committee and with those of the Code of Ethics of the World Medical Association (Declaration of Helsinki).

\section{REFERÊNCIAS}

1. Doherty CM, Forbes RB. Diagnostic Lumbar Puncture. Ulster Med J. 2014:83:93-102.

2. The International Classification of Headache Disorders [consultado agosto 2017] Disponível em: http://www.ichd-3.org.

3. Kwak KH. Postdural puncture headache. Korean J Anesthesiol. 2017;70:136-43.

4. Ahmed SV, Jayawarna C, Jude E. Post lumbar puncture headache: diagnosis and management. Postgrad Med J. 2006;82:713-6.

5. Sinnaeve L, Vanopdenbosch L, Paemeleire K. Association of Cerebral Venous Thrombosis and Intracranial Hypotension: Review of 3 Cases. J Stroke Cerebrovasc Dis. 2017;26:165-9.

6. Ghaleb A, Khorasani A, Mangar D. Post-dural puncture headache. Int J Gen Med. 2012;5:45-51. 